\title{
Degradation of Para-Phenylenediamine in Aqueous Solution by Photo-Fenton Oxidation Processes
}

\author{
Shridhara $\mathrm{TN}^{1^{*}}$, Chethan $\mathrm{DM}^{1}$, Manu $\mathrm{B}^{2}$ and Indresh $\mathrm{N}^{2}$ \\ ${ }^{1}$ NMAM Institute of Technology, Nitte, Karkala, - 574110, Karnataka, India \\ ${ }^{2}$ National Institute of Technology, Surathkal, - 575025, Mangalore, India
}

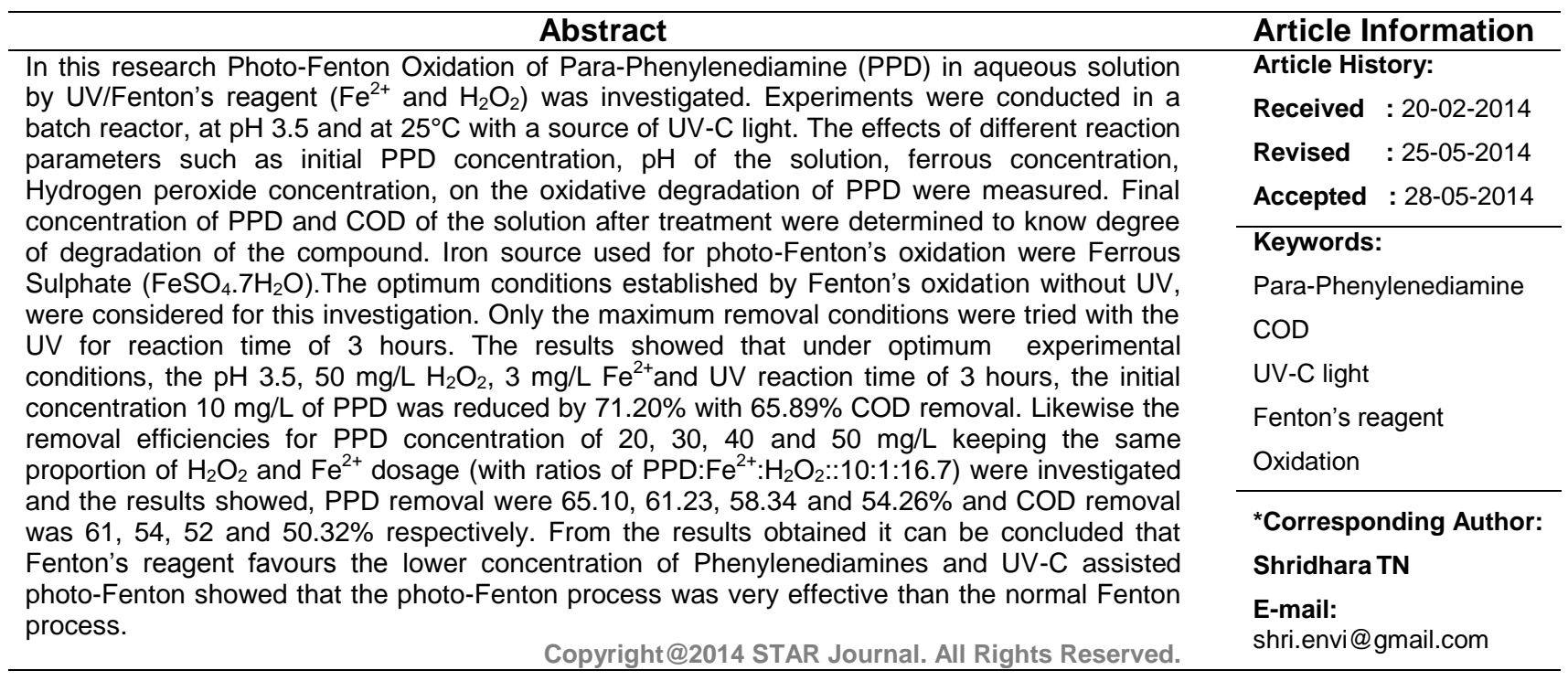

\section{INTRODUCTION}

Para-Phenylenediamine (PPD) is a non-biodegradable organic chemical that is widely used as ingredient in various product including hair dyes. Sensitization to PPD is a well-known cause for Allergic Contact Dermatitis (ACD). Moreover, ACD because of PPD containing skin paints (temporary tattoos) are increasingly reported (Badawy et al., 2006). Up to now, it is not completely understood why certain individuals are more likely to develop ACD after exposure to PPD than others. Genetic factors influencing the sensitization or reactivation process may have impact on the individual susceptibility (Blcmeke et al., 2008). Many chemical treatment techniques have been emerged in the last few decades to degrade non-biodegradable organic pollutants. Among these treatment techniques, the Advanced Oxidation Processes (AOP) appears to be promising and reported to be effective for the degradation of non-biodegradable organic pollutants like PPD in water.

The AOP have proved capable of degrading the ParaPhenylenediamine from aqueous solutions (Klavarioti et al., 2009). These Processes are based on the generation of hydroxyl radical, which is a powerful oxidant. Among AOPs, Fenton and Photo-Fenton Oxidation processes have emerged as the most promising methods for the treatment of organic non-biodegradable pollutants (Manu et al., 2011). In a comprehensive review, Neyens and Baeyens (2003) have indicated that the Fenton's Oxidation is very effective in the removal of many hazardous organic pollutants from water and wastewaters.

The photo-Fenton reaction involves irradiation with solar or UV light which significantly increases the rate of pollutant degradation by photo reduction of $\mathrm{Fe}^{3+}$ to $\mathrm{Fe}^{2+}$. Fenton's reaction generates hydroxyl radicals and photoFenton reactions reduce the $\mathrm{Fe}^{3+}$ to $\mathrm{Fe}^{2+}$, thus leading to production of additional $\mathrm{OH}$ radicals and continuous regeneration of $\mathrm{Fe}^{2+}$ in a catalytic way (Sun and Pignatello, 1993). It is also observed that the additional amounts of $\mathrm{OH}$ radicals are also produced from the direct photolysis of $\mathrm{H}_{2} \mathrm{O}_{2}$ (Laat et al., 1999).

Among all these advanced oxidation processes use combinations of oxidants, ultraviolet irradiation and catalysts to generate hydroxyl radicals $\left(\mathrm{OH}^{\circ}\right)$ in solutions and have attracted interest for the degradation of Phenylenediamines. Among all these Fenton reactions (mainly $\mathrm{Fe}^{2+} / \mathrm{H}_{2} \mathrm{O}_{2}$ ) generates hydroxyl radicals $\left(\mathrm{OH}^{\circ}\right)$ by means of the reaction of $\mathrm{H}_{2} \mathrm{O}_{2}$ with ferrous ion, which is 


\section{Shridhara et al.,}

efficient and low cost method, taking place at room temperatures and at atmospheric pressure compared to all other advanced oxidation processes (Manu et al., 2011).

Fenton oxidation systems have two limitations: (1) a large production of iron sludge, and (2) a slow reduction of ferric ions by $\mathrm{H}_{2} \mathrm{O}_{2}$ in their application (Walling, 1975; De Laat and Gallard, 1999). However, Photo-Fenton Oxidation was suggested to overcome the limitations of the Fenton oxidation systems.

This study focused on the removal efficiency of ParaPhenylenediamine and to optimize the photo-Fenton's dosage, $\mathrm{pH}$, with respect to PPD concentration. PhotoFenton's reagent is reported to oxidize all kinds of organic contaminants and hence its evaluation could be a worthwhile effort.

\section{MATERIALS AND METHODS}

\section{Materials}

The materials include Para-Phenylenediamine was purchased from Merck manufacturer, India and was used as obtained. Hydrogen Peroxide $(50 \% \mathrm{w} / \mathrm{w})$ and Ferrous Sulfate $\left(\mathrm{FeSO}_{4} .7 \mathrm{H}_{2} \mathrm{O}\right)$ are purchased from Merck. The chemicals were used as received in the Fenton's Oxidation Process. Hydrochloric acid ( $\mathrm{HCl}, 35 \%$ purity), Sulfuric acid $\left(\mathrm{H}_{2} \mathrm{SO}_{4}, 98 \%\right.$ purity), Sodium hydroxide $(\mathrm{NaOH}, \quad 98 \%$ purity), were also used in the experiments. PPD aqueous stock solution of $1000 \mathrm{mg} / \mathrm{L}$ concentration is prepared every week with Millipore Elix-3 deionized water and stored in the dark at $4^{\circ} \mathrm{C}$.

\section{Experimental Procedure}

The oxidation experiments were carried out at ambient temperature $\left(27 \pm 3^{\circ} \mathrm{C}\right)$ in batch reactors. Initially, the reaction conditions like $\mathrm{pH}, \mathrm{H}_{2} \mathrm{O}_{2}$ dosage, and $\left[\mathrm{H}_{2} \mathrm{O}_{2}\right] /$ $\left[\mathrm{Fe}^{2+}\right]$ ratio were optimized in the Fenton oxidation of $\mathrm{PPD}$ and the further Fenton and photo-Fenton experiments were conducted with the optimum conditions. The effect of initial PPD concentration on the degradation and mineralization of PPD by both Fenton oxidation and UV-C Fenton oxidation were evaluated and the results were compared. PPD samples were analyzed using UV-VIS double beam spectrophotometer.

All the Fenton and photo-Fenton experiments were carried out in batch reactors. Figure 1 shows the photoreactor, consists of enclosed chamber comprising a reactor (2L volume beaker), 8W UV-C Philips lamp covered with a quartz jacket and connected to AC power, magnetic stirrer. A $1000 \mathrm{~mL}$ solution of required PPD concentration is prepared from the stock PPD solution and was taken in the 2- liter reactor. The intrinsic $\mathrm{pH}$ of the wastewater was 6.32 and the Initial $\mathrm{pH} 3.5$ of the solutions was maintained using $0.1 \mathrm{~N} \mathrm{H}_{2} \mathrm{SO}_{4}$ and $0.1 \mathrm{~N}$ $\mathrm{NaOH}$. Required amount of $\mathrm{H}_{2} \mathrm{O}_{2}$ was added to the reactor bath to initiate the reaction. The mixture of PPD solution and Fenton's reagent is stirred with magnetic stirrer during treatment.

The PPD solution samples were taken out for analysis at pre-defined time intervals, filtered through $0.45-\mu \mathrm{m}$ Millipore filter membrane for COD analysis, and filtered through a $0.45 \mu \mathrm{m}$ Millipore Syringe filter for determination of PPD concentration by using UV-VIS spectrophotometer analysis.
Sci. Technol. Arts Res. J., April-June 2014, 3(2): 88-92

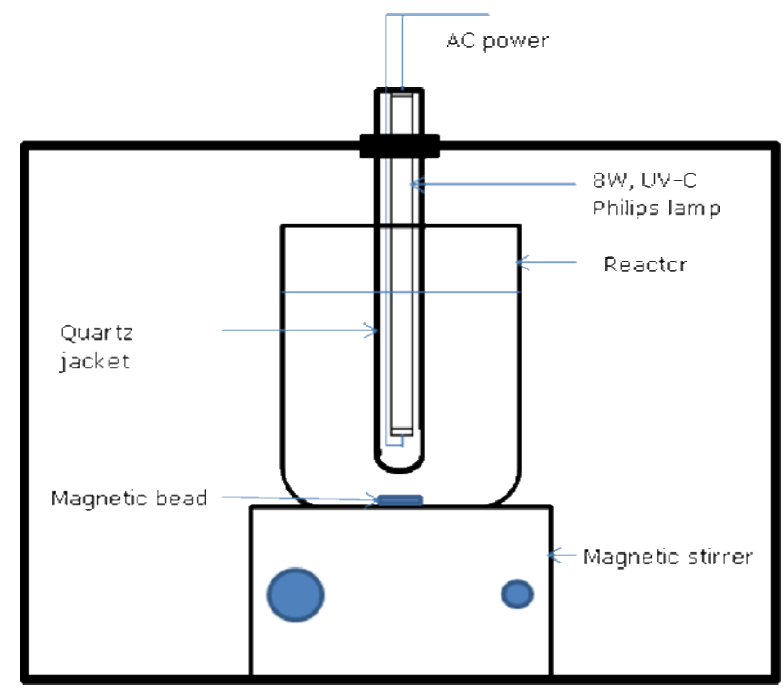

Figure 1: Schematic representation of the photochemical reactor

\section{Analytical Methods}

UV-VIS spectrum is recorded from 190 to $500 \mathrm{~nm}$ using UV-VIS spectrophotometer and the absorbance peak of PPD is observed to be at wavelength $233.4 \mathrm{~nm}$. The concentration of PPD in the aqueous solution at wavelength $233.4 \mathrm{~nm}$ is measured immediately after removal of samples from the reactor using the standard curve, which has already been calibrated with UV-VIS double beam spectrophotometer. The $\mathrm{pH}$ is measured with a digital $\mathrm{pH}$ meter (Lovibond- $\mathrm{pH} 100$ ). The COD of the samples is determined by closed reflux titrimetric method as per the procedure outlined in the Standard Methods (APHA, 2005).

The initial COD before treatment was due to PPD in synthetic wastewater and the COD after treatment was due to residual PPD if present and other reaction intermediates, if any, present in the aqueous solution. Final COD is quantitatively corrected for $\mathrm{H}_{2} \mathrm{O}_{2}$ interference according to the correlation equation given by Kang et al. (1999). The Iron concentration is measured by Thiocynate colorimetric Method using Spectrocolorimeter (PC-Spectroll, Lovibond). The $\mathrm{H}_{2} \mathrm{O}_{2}$ concentration was determined by iodometric titration method (Kolthoff, 1920).

\section{RESULTS AND DISCUSSION}

In this present study laboratory scale experiments were conducted for PPD using ferrous sulphate $\left(\mathrm{FeSO}_{4} .7 \mathrm{H}_{2} \mathrm{O}\right)$ as iron source in the Photo-Fenton's oxidation. Synthetic PPD solutions were prepared at different initial concentrations of 10, 20,30,40 and 50 $\mathrm{mg} / \mathrm{L}$.

\section{Effect of $\mathrm{pH}$}

Effect of $\mathrm{pH}$ with Fenton's reagent was studied for $\mathrm{pH}$ range of 2.0, 2.5, 3.0, 3.5, 4.0 and 4.5. Experiments were conducted by adding the ratio of $\mathrm{H}_{2} \mathrm{O}_{2}$ : Fe::10:1 $\left(\mathrm{H}_{2} \mathrm{O}_{2}\right.$ : $\mathrm{Fe}=66: 6.6 \mathrm{mg} / \mathrm{L})$ to $\mathrm{PPD}$ concentration of $10 \mathrm{mg} / \mathrm{L}$ with a reaction mixture volume of $1000 \mathrm{ml}$. The maximum PPD reduction and COD removal are found to be $56 \%$ and $71 \%$ respectively at $\mathrm{pH} 3.5$ as shown in figure 2 . The PPD removal efficiencies were less for the other values of $\mathrm{pH}$.

At $\mathrm{pH}$ 3.5, PPD removal is maximum and it might be due to the formation of more $\mathrm{Fe}(\mathrm{OH})^{+}$which has much higher activity than $\mathrm{Fe}^{2+}$ in Fenton's oxidation (Badawy et 


\section{Shridhara et al.,}

al., 2006). When $\mathrm{pH}>3$, oxidation efficiency rapidly decreases due to auto- decomposition of $\mathrm{H}_{2} \mathrm{O}_{2}$ affecting the production of $\mathrm{OH}^{*}$ radicals (Badawy and Ali, 2006) and deactivation of ferrous catalyst with the formation of ferric hydroxide precipitates (Luis et al., 2009). When $\mathrm{pH}<3$, the reaction of $\mathrm{H}_{2} \mathrm{O}_{2}$ with $\mathrm{Fe}^{2+}$ was seriously affected to reduce hydroxyl radical production and water is formed by the reaction of $\mathrm{OH}$ radicals with $\mathrm{H}^{+}$ions (Lucas and Peres 2006).

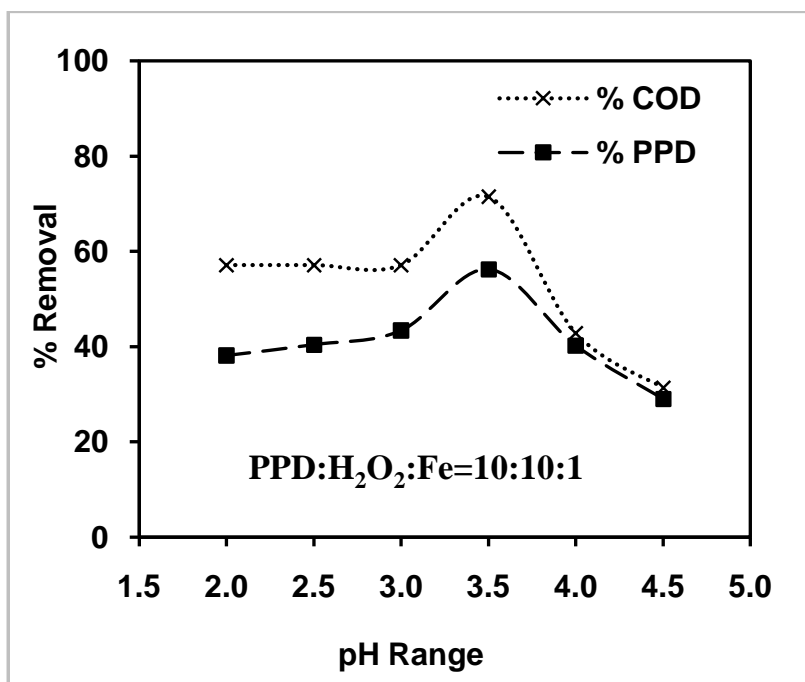

Figure 2: Effect of $\mathrm{pH}$ on PPD and COD removal during photo-Fenton's oxidation

\section{Effect of UV Radiation}

Kinetic studies for the degradation for removal of PPD were conducted for 24 hours and the reaction time was optimized. In the Figure 3, it is seen that PPD and COD removal increased till 180 minutes ( 3 hours) and there was no much degradation later on. Hence to optimize the photo degradation of PPD in photo-Fenton's oxidation the irradiation was taken as 180 minutes for the rest of the experiments. This proved to be economical and efficient than Fenton's Oxidation (Dark Fenton reactions).

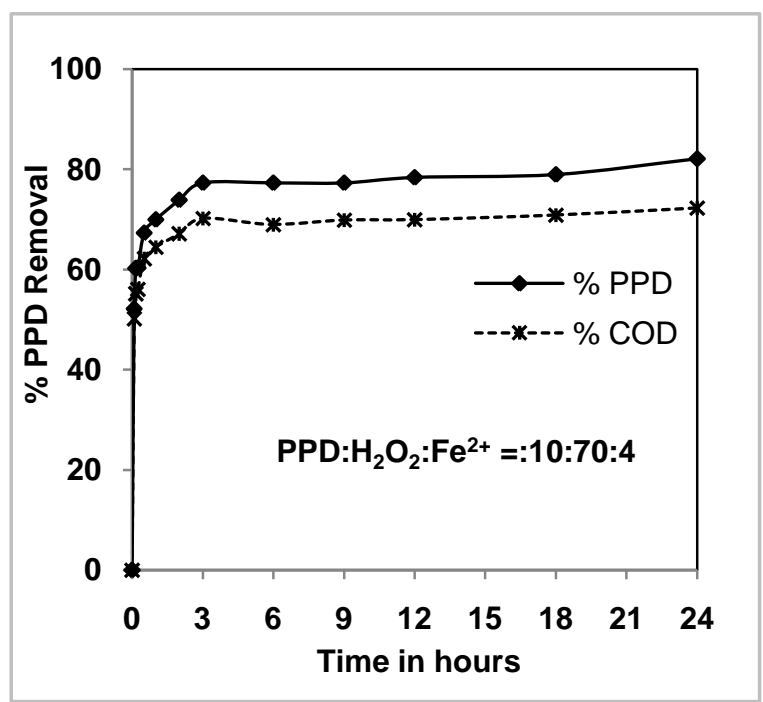

Figure 3: Kinetic studies for the degradation of PPD and COD for 24 hours UV radiation
Sci. Technol. Arts Res. J., April-June 2014, 3(2): 88-92

Photo Degradation of PPD with Ferrous Sulphate Iron as Catalyst in PFO

After optimizing the favourable $\mathrm{pH}$, a wide range of $\mathrm{Fe}^{2+} / \mathrm{H}_{2} \mathrm{O}_{2}$ ratios were investigated for the effective degradation of the compounds. The following table 1 shows the various doses of $\mathrm{Fe}^{2+} / \mathrm{H}_{2} \mathrm{O}_{2}$ designed for PFO of PPD

Table 1: Design of experiments for degradation of PPD

\begin{tabular}{ccccc}
\hline $\begin{array}{c}\mathbf{C}_{0} \\
\mathbf{M g} / \mathbf{L}\end{array}$ & {$[\mathbf{p H}]_{0}$} & $\begin{array}{c}\text { UV- Time } \\
\text { (in min) }\end{array}$ & $\begin{array}{c}{\left[\mathrm{H}_{\mathbf{2}} \mathbf{O}_{2}\right]_{\mathbf{0}}} \\
\mathbf{~} \mathbf{g} / \mathbf{L}\end{array}$ & $\begin{array}{c}{\left[\mathrm{Fe}^{2+}\right]_{\mathbf{0}}} \\
\mathbf{m g} / \mathbf{L}\end{array}$ \\
\hline 10 & 3.5 & 180 & 50 & 3 \\
20 & 3.5 & 180 & 100 & 6 \\
30 & 3.5 & 180 & 150 & 9 \\
40 & 3.5 & 180 & 200 & 12 \\
50 & 3.5 & 180 & 250 & 15 \\
\hline
\end{tabular}

Effect of $\mathrm{Fe}^{2+}$ and $\mathrm{H}_{2} \mathrm{O}_{2}$ in Photo-Fenton's Oxidation of PPD

The dosage of hydrogen peroxide and iron concentrations applied is shown in figure 4 and the respective PPD removal in the Fenton's oxidation. The figure 4 shows that for PPD concentration of $10 \mathrm{mg} / \mathrm{L}$, maximum degradation was at $50 \mathrm{mg} / \mathrm{L}$ of $\mathrm{H}_{2} \mathrm{O}_{2}$ and 3 $\mathrm{mg} / \mathrm{L}$ of $\mathrm{Fe}^{2+}$.

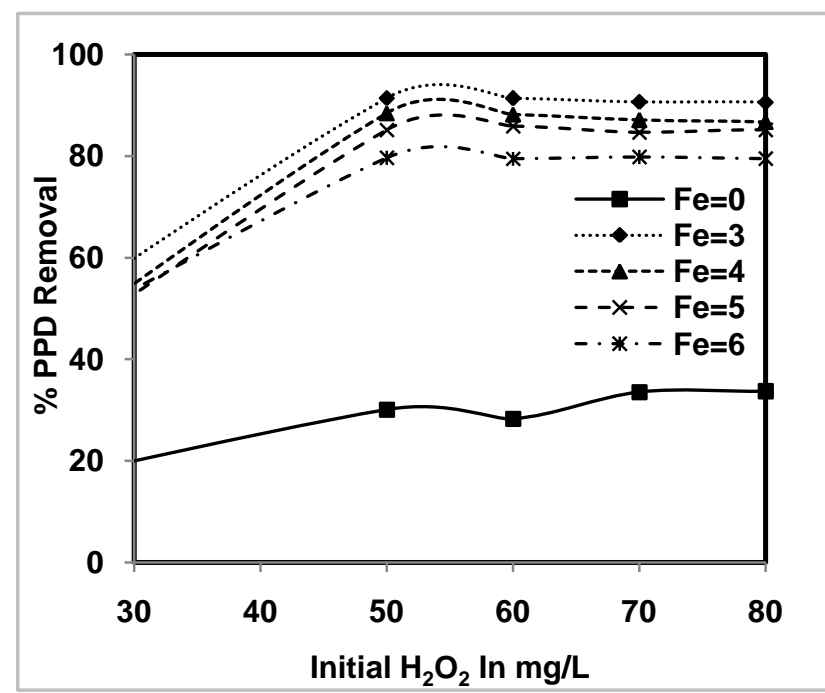

Figure 4: Plot of PPD removal of initial concentration 10 $\mathrm{mg} / \mathrm{L}$ against various doses of $\mathrm{H}_{2} \mathrm{O}_{2}$ and iron

PPD and COD Removal at Different Initial Concentrations of PPD 10, 20, 30, 40 and $50 \mathrm{mg} / \mathrm{L}$ against Various Dosages of UV Radiation in PFO

PPD concentration of $10 \mathrm{mg} / \mathrm{L}$, maximum degradation was at $50 \mathrm{mg} / \mathrm{L}$ of $\mathrm{H}_{2} \mathrm{O}_{2}$ and $3 \mathrm{mg} / \mathrm{L}$ of $\mathrm{Fe}^{2+}$ and UV dosage of 180 minutes. For initial PPD concentration of $10 \mathrm{mg} / \mathrm{L}$, at a ratio of $\mathrm{Fe}^{2+}: \mathrm{H}_{2} \mathrm{O}_{2}:: 1: 16.67$ removal achieved was $71.20 \%$ with $65.89 \%$ of COD removal. This was the highest removal achieved in PFO of PPD. The other high ranges of $\mathrm{Fe}^{2+}$ did not prove to be efficient, because excessive ferrous ions can be dominant scavengers of hydroxyl radicals generated during PFO (Tang et al., 1996 and Walling, 1975). 
Shridhara et al.,

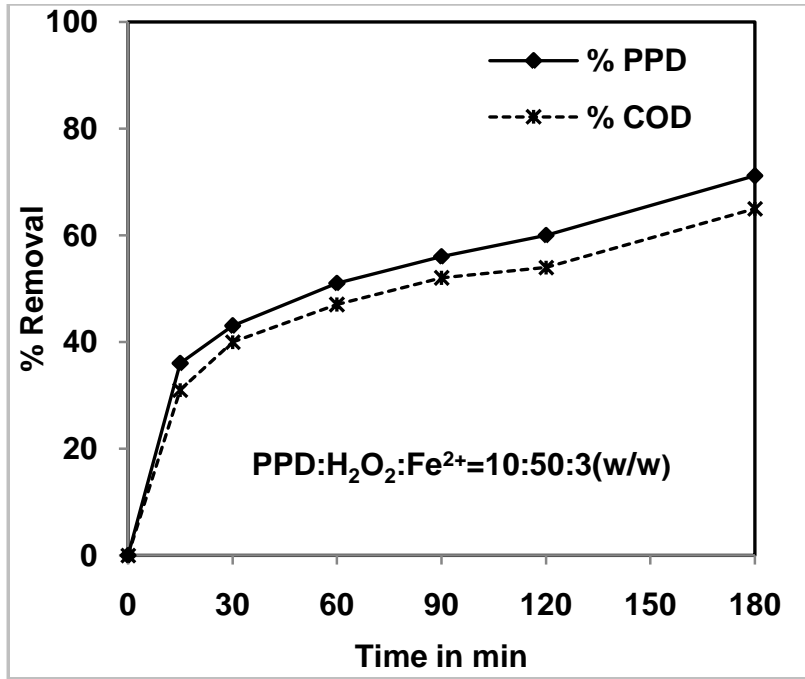

Figure 5: Plot of PPD and COD removal for $10 \mathrm{mg} / \mathrm{L}$ PPD concentration against various dosages of UV radiation

For PPD concentration of $20 \mathrm{mg} / \mathrm{L}$, maximum degradation was at $100 \mathrm{mg} / \mathrm{L}$ of $\mathrm{H}_{2} \mathrm{O}_{2}$ and $6 \mathrm{mg} / \mathrm{L}$ of $\mathrm{Fe}^{2+}$ and UV dosage of 180 minutes resulting in $65.10 \%$ PPD with $61.8 \%$ of COD removal as shown in Figure 6 .

The Figure 7 shows that the increase in initial concentration of PPD, degradation rates decrease. This is because a relatively lower concentration of $\mathrm{OH}^{*}$ results from the increasing concentration of PPD while the dosage of $\mathrm{H}_{2} \mathrm{O}_{2}$ and $\mathrm{Fe}^{2+}$ remains the same, which leads to a decreasing of the degradation efficiency of PPD. A higher concentration increases the number of pollutant molecules, but not the $\mathrm{HO}^{\circ}$ radical concentration, and so the removal rate diminishes (Marco, 2009). A maximum of $61.23 \%$ PPD removal and $54.59 \%$ COD removal were achieved at $\mathrm{H}_{2} \mathrm{O}_{2} 150 \mathrm{mg} / \mathrm{L}$ and $\mathrm{Fe}^{2+} 9 \mathrm{mg} / \mathrm{L}$ and UV dosage of 180 minutes.

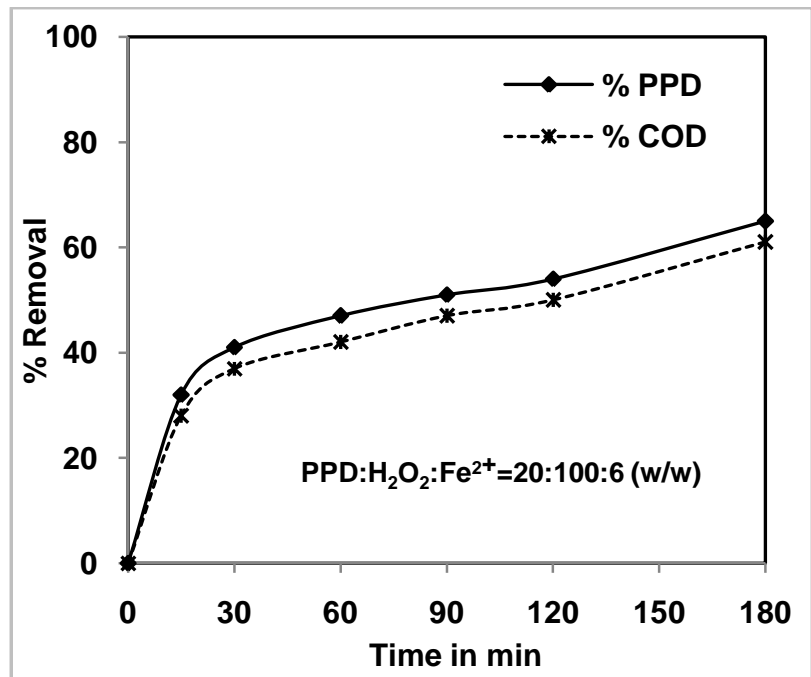

Figure 6: Plot of PPD and COD removal for $20 \mathrm{mg} / \mathrm{L}$ PPD concentration against various dosages of UV radiation.
Sci. Technol. Arts Res. J., April-June 2014, 3(2): 88-92

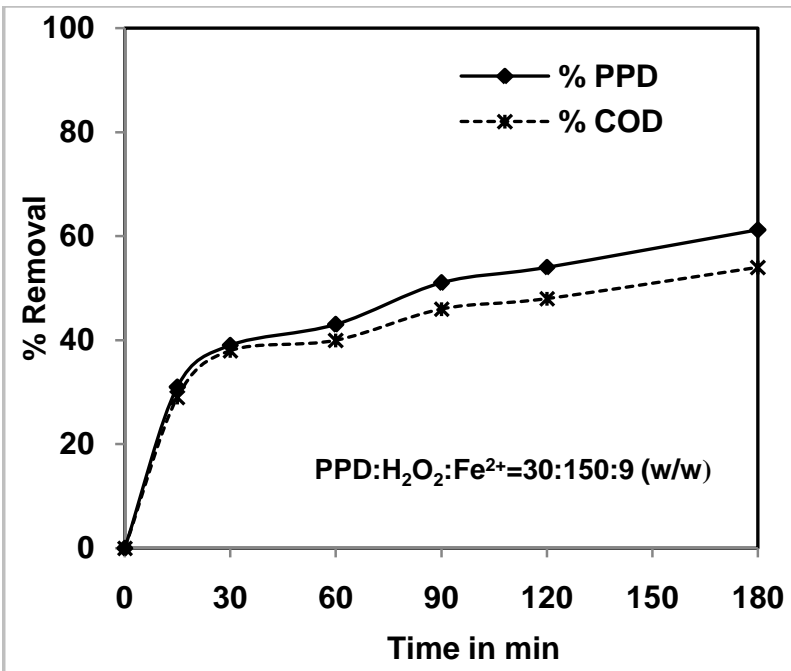

Figure 7: Plot of PPD and COD removal for $30 \mathrm{mg} / \mathrm{L}$ PPD concentration against various dosages of UV radiation

Degradation studies for the PPD concentration 40 $\mathrm{mg} / \mathrm{L}$ resulted in decrease in removal rates. At low concentration of pollutants, the percentage conversion is higher compared to that at higher concentration (Rathi et al., 2003). A maximum of $58.12 \%$ PPD removal and $52.84 \%$ COD removal were achieved at $\mathrm{H}_{2} \mathrm{O}_{2} 200 \mathrm{mg} / \mathrm{L}$ and $\mathrm{Fe}^{2+} 12 \mathrm{mg} / \mathrm{L}$ and UV dosage of 180 minutes as shown in figure 8 . However there was no significant improvement in removal efficiencies.

Similarly for PPD initial concentrations of $50 \mathrm{mg} / \mathrm{L}$, PPD removal was decreased to $54.26 \%$ with COD removal of $50.60 \%$. The ratio of $\mathrm{Fe}^{2+}: \mathrm{H}_{2} \mathrm{O}_{2}:: 1: 16.67$ as shown in the figure 9 which is same for all the initial concentrations of PPD.

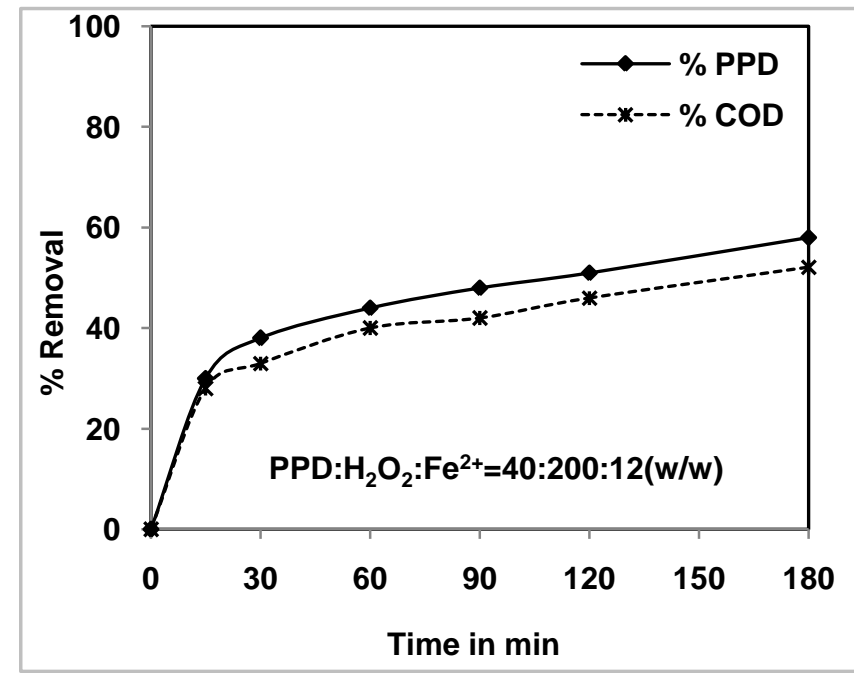

Figure 8: Plot of PPD and COD removal for $40 \mathrm{mg} / \mathrm{L}$ PPD concentration against various dosages of UV radiation.

This indicates that the PFO of Para phenylenediamines is best at lower concentrations, although there is an increase in $\mathrm{Fe}^{2+} / \mathrm{H}_{2} \mathrm{O}_{2}$ concentrations in equal proportion to the initial concentration. Also the presence of excess of Fenton's reagent itself is a hindrance to effectiveness of Photo Fenton Oxidation for pollutant removal. The results obtained for higher concentrations of PPD were not encouraging. 
Shridhara et al.,

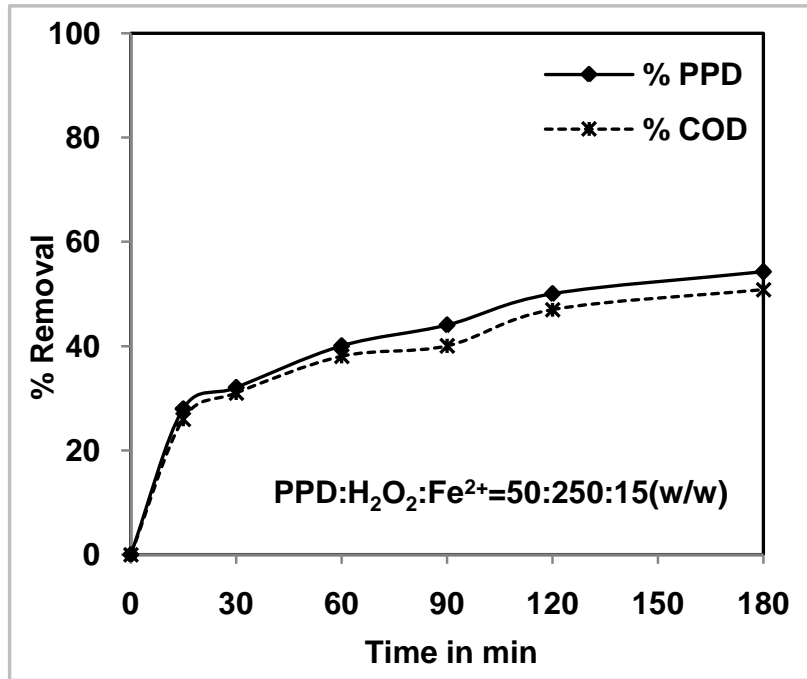

Figure 9: Plot of PPD and COD removal for $50 \mathrm{mg} / \mathrm{L}$ PPD concentration against various dosages of UV radiation

\section{CONCLUSIONS}

From the results obtained from the study, it can be concluded that Fenton's reagent favours at the lower concentration of PPD. UV-Fenton process is observed to be an effective treatment method over Fenton process for the removal of Para Phenylenediamines in aqueous solutions. Photo Fenton's oxidation process may be applied in-situ for the treatment of Para Phenylenediamines in surface and ground water.

\section{REFERENCES}

APHA (2005). Standard methods for the Examination of Water and Wastewater. 21 $1^{\text {th }}$ Edition (C) APHA, AWWA, WEF. Washington, DC.

Badawy, M.I., Ghaly M.Y., Gad-Allah T.A. (2006). Advanced oxidation processes for the removal of organophosphorus pesticides from wastewater. Desalination 194: 166-175.

Blçmeke, B., Brans, R., Dickel, H., Bruckner, T., Erdmann, S., Heesen, M., Merk, H.F. and Coenraads' P.J. (2009). Association between TNFA-308 G/A polymorphism and sensitization to para-phenylenediamine: a case-control study. Allergy 64: 279-283

De Laat, J. and Gallard, H. (1999). Catalytic decomposition of hydrogen peroxide by $\mathrm{Fe}(\mathrm{III})$ in homogeneous aqueous solution: Mechanism and kinetic modeling. Environmental Science and Technology 33(16): 2726-2732
Sci. Technol. Arts Res. J., April-June 2014, 3(2): 88-92

Kang, Y.W., Cho, M.J. and Hwang, K.Y. (1999). Correction of Hydrogen Peroxide interference on Standard Chemical Oxygen demand test. Water Research 33(5):1247-1251.

Klavarioti, M., Mantzavinos, D. and Kassinos, D. (2009). Removal of residual pharmaceuticals from aqueous systems by advanced oxidation processes - Review article. Environment International 35(2):402-17.

Kolthoff, I.M. (1920). Chem Weekblad 17: 197.

Laat, D.J., Gallard, H., Ancelin, S. and Legube, B. (1999). Comparative study of the oxidation of atrazine and acetone by $\mathrm{H} 2 \mathrm{O} 2 / \mathrm{UV}, \mathrm{Fe}(\mathrm{III}) / \mathrm{UV}, \mathrm{Fe}(\mathrm{III}) / \mathrm{H} 2 \mathrm{O} 2 / \mathrm{UV}$ and $\mathrm{Fe}(\mathrm{II})$ or $\mathrm{Fe}(\mathrm{III}) / \mathrm{H} 2 \mathrm{O} 2$. Chemosphere 39: 2693-2706.

Lucas, M.S. and Peres, J.A. (2006). Decolorization of the azo dye Reactive Black 5 by Fenton and photo-Fenton oxidation. Dyes and Pigments 71: 236-244.

Luis, A.D., Lombranda, J.I., Varona, F. and Menendez, A. (2009). Kinetic Study and hydrogen peroxide consumption of phenolic compounds oxidation by Fenton's reagent. Korean Journal of Chemical Engineering 26(1): 48-56.

Manu, B. and Mahamood. (2011). Degradation of Paracetamol in Aqueous Solution by Fenton Oxidation and Photo-Fenton Oxidation Processes Using Iron from Laterite Soil as Catalyst. International Journal of Earth Sciences and Engineering 4(6): 1103-1110.

Manu, B. and Mahamood. (2011). Enhanced degradation of paracetamol by UV-C supported photo-Fenton process over Fenton oxidation. Water Science and Technology 64(12): 2433 - 2438

Marco Paulo Gomes De Sousa Lucas. (2009). Application of advanced oxidation processes to Wastewater treatment. Doctoral thesis. Department of Chemistry. University of Trás-os-Montes and Alto Douro.

Neyens, E. and Baeyens, J. (2003). A review of classic Fenton's peroxidation as an advanced oxidation technique. Journal of Hazardous Materials B98: 33-50

Rathi, A., Rajor, H.K., R.K. and Sharma, R.K., (2003). Photodegradation of direct yellow 12 using UV/ $\mathrm{H}_{2} \mathrm{O}_{2} / \mathrm{Fe}^{2+*}$. Journal of Hazardous Materials B102: 231241.

Sun, Y., Pignatello, J.J. 1993. Photochemical reactions involved in the total mineralization of 2, 4-D by $\mathrm{Fe} 3+/$ H2O2/UV. Environmental Science and Technology 27: 304-310.

Tang, W.Z., Huang, C.P. (1996). 2,4-dichlorophenol oxidation kinetics by Fenton's reagent". Environmental Technology (17): 1371

Walling, C. (1975). Fenton's reagent revisited. Accounts of Chemical Research (8): 25. 